\title{
Facile fabrication of multi-pocket nanoparticles with stepwise size transition for promoting deep penetration and tumor targeting
}

\author{
Xingyu Hou' ${ }^{1}$, Dan Zhong ${ }^{1}$, Yunkun Li ${ }^{1}$, Hongli Mao ${ }^{2}$, Jun Yang ${ }^{3}$, Hu Zhang ${ }^{4}$, Kui Luo ${ }^{1}$, Qiyong Gong ${ }^{1}$ and
} Zhongwei $\mathrm{Gu}^{1,2^{*}}$

\begin{abstract}
Background: Nanocarriers-derived antitumor therapeutics are often associated with issues of limited tumor penetration and dissatisfactory antitumor efficacies. Some multistage delivery systems have been constructed to address these issues, but they are often accompanied with complicated manufacture processes and undesirable biocompatibility, which hinder their further application in clinical practices. Herein, a novel dual-responsive multi-pocket nanoparticle was conveniently constructed through self-assembly and cross-linking of amphiphilic methoxypolyethylene glycol-lipoic acid (mPEG-LA) conjugates to enhance tumor penetration and antitumor efficacy.

Results: The multi-pocket nanoparticles (MPNs) had a relatively large size of $170 \mathrm{~nm}$ at physiological pH which results in prolonged blood circulation and enhanced accumulation at the tumor site. But once extravasated into acidic tumor interstices, the increased solubility of PEG led to breakage of the supramolecular nanostructure and dissolution of MPNs to small-sized $(<20 \mathrm{~nm}$ ) nanoparticles, promoting deep penetration and distribution in tumor tissues. Furthermore, MPNs exhibited not only an excellent stable nanostructure for antitumor doxorubicin (DOX) loading, but rapid dissociation of the nanostructure under an intracellular reductive environment. With the capacity of long blood circulation, deep tumor penetration and fast intracellular drug release, the DOX-loaded multi-pocket nanoparticles demonstrated superior antitumor activities against large 4T1 tumor $\left(\sim 250 \mathrm{~mm}^{3}\right)$ bearing mice with reduced side effect.
\end{abstract}

Conclusions: Our facile fabrication of multi-pocket nanoparticles provided a promising way in improving solid tumor penetration and achieving a great therapeutic efficacy.

Keywords: Drug delivery, Particle size, Tumor penetration, Disulfide cross-linking, Facile preparation

*Correspondence: zwgu@scu.edu.cn; zwgu@njtech.edu.cn

${ }^{1}$ Huaxi MR Research Center (HMRRC), Department of Radiology, Functional and Molecular Imaging Key Laboratory of Sichuan Province, National Clinical Research Center for Geriatrics, West China Hospital, Sichuan University, Chengdu 610041, People's Republic of China Full list of author information is available at the end of the article

\section{Introduction}

Nanoscale supramolecular assemblies have been extensively exploited as drug carriers for cancer therapy over the last decades due to their improved drug solubility and pharmacokinetics, enhanced permeability and retention (EPR) at tumor site, and reduced systemic side effects [1-3]. Nevertheless, conventional selfassemblies formed via weak non-covalent hydrophobic

c) The Author(s) 2021. This article is licensed under a Creative Commons Attribution 4.0 International License, which permits use, sharing, adaptation, distribution and reproduction in any medium or format, as long as you give appropriate credit to the original author(s) and the source, provide a link to the Creative Commons licence, and indicate if changes were made. The images or other third party material in this article are included in the article's Creative Commons licence, unless indicated otherwise in a credit line to the material. If material is not included in the article's Creative Commons licence and your intended use is not permitted by statutory regulation or exceeds the permitted use, you will need to obtain permission directly from the copyright holder. To view a copy of this licence, visit http://creativeco mmons.org/licenses/by/4.0/. The Creative Commons Public Domain Dedication waiver (http://creativecommons.org/publicdomain/ zero/1.0/) applies to the data made available in this article, unless otherwise stated in a credit line to the data. 
interactions are inherently unstable in vivo because of their potential dynamic dissociation upon dilution, which often leads to premature drug release before reaching the tumor sites $[4,5]$. Although some chemical approaches (e.g., cleavable covalent cross-linking via disulfide bonds [6-8], boronate bonds [9] and ketal bonds [10]) have been adopted to stabilize the assemblies and trigger site-specific drug release, features such as sophisticated nanostructures, biocompatibility and degradability, facile manufacture and low cost [11] are fundamental prerequisites for biomedical applications in antitumor drug delivery.

On the other hand, currently approved nanoscaled assemblies provide modest therapeutic efficacies, probably due to poor tumor penetration efficiencies resulted from abnormal tumor vasculature, elevated interstitial fluid pressure and dense interstitial matrix [12, 13]. Generally, large nanoparticles with a diameter of $70 \sim 200 \mathrm{~nm}$ are suitable for passive tumor accumulation via the EPR effect, but they have huge diffusional hindrance in the interstitial space [14]. On the contrary, small-sized nanoparticles $(<30 \mathrm{~nm})$ have much better tumor penetration, while associated with a short half-life and poor tumor accumulation due to rapid elimination during circulation $[14,15]$. Therefore, a size-switchable delivery system: a large size to achieve long blood circulation time and effective tumor accumulation before reaching the tumor site, but a small size for enhanced tumor penetration and uniform distribution once they are extravasated into tumor tissue, is pursued to improve therapeutic efficacies.

Some size-switchable delivery systems that shrank their sizes in response of exogenous stimuli (e.g., light) or endogenous biological stimuli (e.g., adenosine triphosphate, enzymes, tumor acidity and reactive oxygen species) showed better tumor accumulation, deeper tumor penetration, and improved cancer treatment efficacy [16-20]. However, considering the difficulty of clinical translation, efforts should be made to reduce the complexity of the system [21]. Herein, we proposed a facile approach to fabricate novel multi-pocket nanoparticles (MPNs) which are size-manipulatable in the tumor acidic extracellular environment and structure-manipulatable to control the release of drug in the intracellular reductive environment (Scheme 1). The multi-pocket nanoparticles were readily prepared from methoxypolyethylene glycol-lipoic acid (mPEG-LA) conjugates through selfassembly and cross-linking in an aqueous solution. Polyethylene glycol (PEG) has been approved for clinical use by the US Food and Drug Administration (FDA) and it has been widely used in biomedical applications on account of its prolonged body-residence time, increased structure stability against proteases or nucleases, and reduction in immunogenicity [22, 23]. Lipoic acid is a natural product in mitochondria and it is usually used as an antioxidant drug for treatment of diabetes [24, 25]. At physiological $\mathrm{pH}$ during blood circulation, the prepared MPNs are expected to have excellent stability with a large
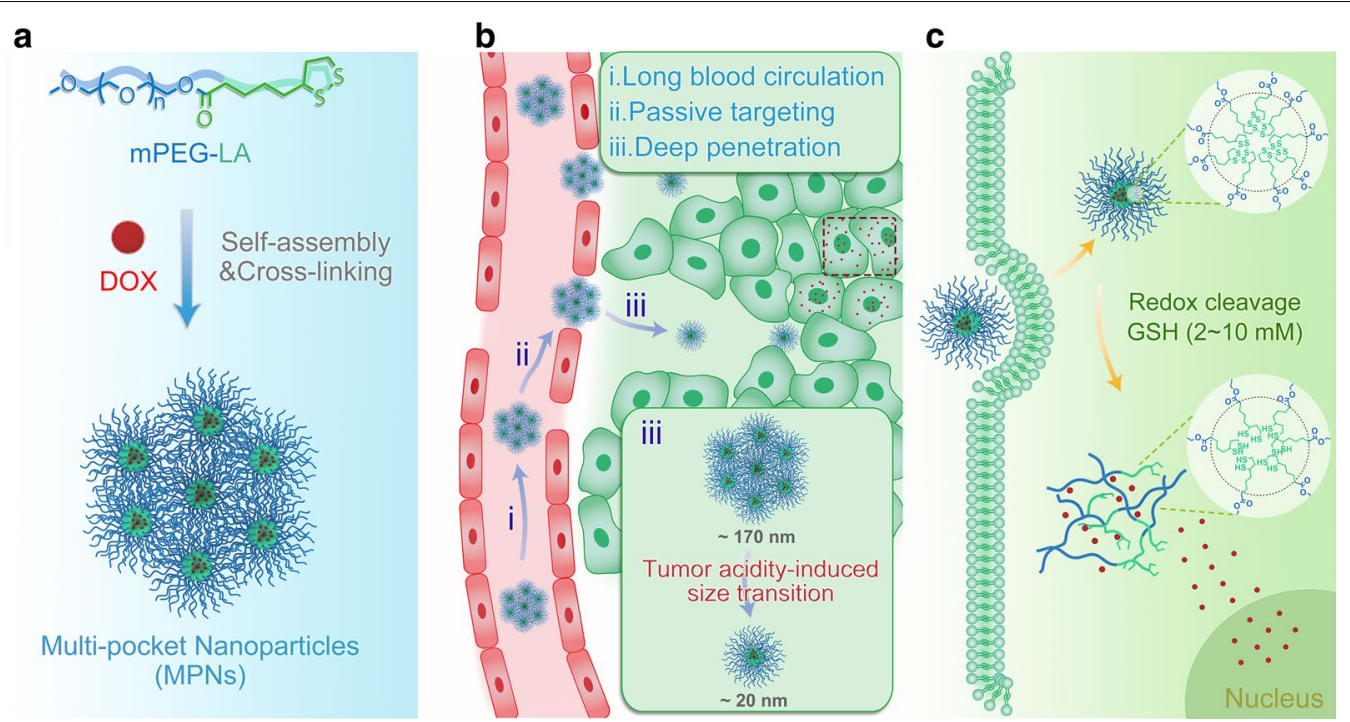

Scheme 1 a Schematic illustration of construction of multi-pocket nanoparticles. $\mathbf{b}$ Elucidation of in vivo drug delivery of DOX-loaded MPNs. (i) A large supramolecular structure and PEGylation of MPNs prolong their blood circulation time; (ii) Prolonged circulation facilitates accumulation of large MPNs at tumor sites via the EPR effect; (iii) Shrinkage of MPNs into small-sized nanoparticles in tumor extracellular acidic environment is favourable for deep tumor penetration. (C) Cleavage of disulfide linkages and subsequent disintegration of small nanoparticles in an intracellular reductive environment lead to DOX release into cytoplasm and nucleus 
size of $\sim 170 \mathrm{~nm}$, have a long blood circulation time and promoted tumor accumulation via the EPR effect. After reaching the tumor site, the tumor extracellular acidity ( $\mathrm{pH}$ 6.5) activates the shrinkage of the supramolecular aggregates into small-sized disulfide cross-linked nanoparticles $(<20 \mathrm{~nm})$ that enables deep tumor penetration to reach more cancer cells. Finally, intracellular glutathione (GSH) at a high concentration cleaves disulfide linkages to promote dissociation of cross-linked nanoparticles, and the drug is rapidly released to exert cytotoxicity against tumor cells.

\section{Results and discussion}

\section{Preparation and characterization of MPNs}

The amphiphilic mPEG-LA conjugates were readily prepared by treating mPEG with lipoic acid. ${ }^{1} \mathrm{H}$ NMR spectrum in Additional file 1: Fig. S1 revealed that lipoic acid was successfully conjugated onto MPEG, and in the matrix-assisted laser desorption/ionization time-of-flight mass spectrum (MALDI-TOF MS) the peaks corresponded to the theoretical $[\mathrm{M}+\mathrm{Na}]^{+}$ions, where $M=264.09+44.03 n$ and $n=$ number of repeat units (Fig. 1a). The amphiphilic mPEG-LA self-assembled into uniform-nanosized spheres in aqueous medium with an average size of $40 \mathrm{~nm}$ and a negative surface charge of $-18.1 \mathrm{mV}$ (Additional file 1: Fig. S2). The critical assembly concentration (CAC) of the mPEG-LA conjugates using pyrene as a fluorescence probe was determined to be $83.18 \mu \mathrm{g} \mathrm{mL}^{-1}$ (Fig. 1b), and this quite high CAC suggested that they may be subjected to dissociate during blood circulation. After cross-linking under catalysis by DTT ( $10 \mathrm{~mol} \%$ relative to the lipoyl units), the mass spectrum exhibited an increased molecular weight with several distributions, and the mass difference between two adjacent distributions equalled to the average molecular weight of the mPEG-LA conjugates, as a consequence of the formation of linear disulfide bonds between lipoyl units (Fig. 1a). Meanwhile, differential
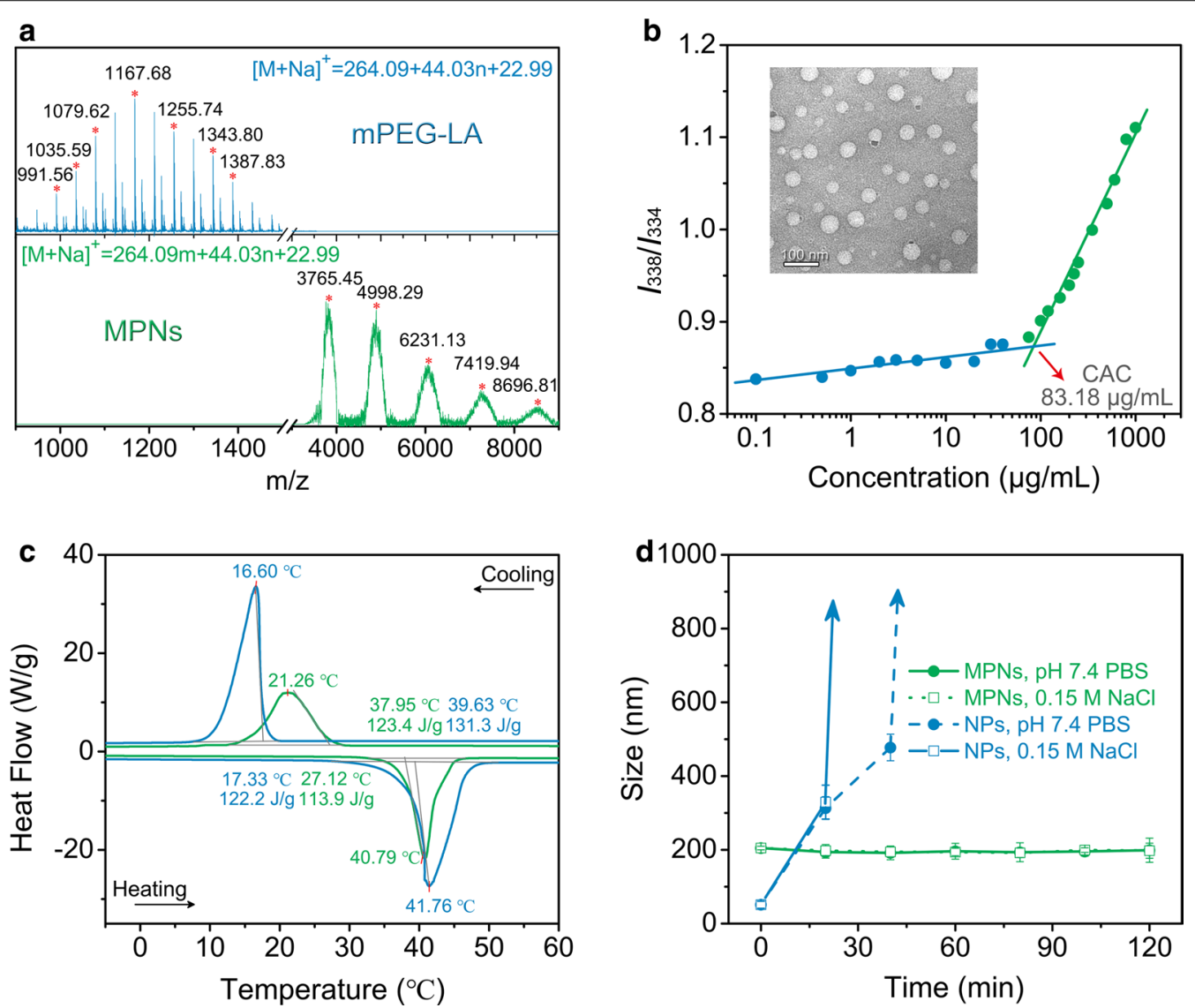

Fig. 1 Characterization of NPs and MPNs. a MALDI-TOF mass spectra of MPEG-LA (blue) and MPNs (green). $\mathbf{b}$ Relationship between the fluorescence intensity ratio $\left({ }_{338} / /_{334}\right)$ and the mPEG-LA concentration in an aqueous solution at $25^{\circ} \mathrm{C}$, [pyrene] $=6.7 \times 10^{-7} \mathrm{M}$. Insert: transmission electron microscope (TEM) image of NPs. Scale bar: $100 \mathrm{~nm}$. c DSC heating and cooling curves $\left(10^{\circ} \mathrm{C} \mathrm{min}{ }^{-1}\right)$ for mPEG-LA (blue curve) and MPNs (green curve) from -5 to $60^{\circ} \mathrm{C}$ in nitrogen atmosphere. $\mathbf{d}$ Time-dependent size variation of NPs and MPNs at a physiological pH and a salt concentration at $25^{\circ} \mathrm{C}(n=3)$ 
scanning calorimetry (DSC) curves revealed a lower melting temperature and a higher crystallization temperature of MPNs than pure mPEG-LA conjugates (Fig. 1c). The difference may be explained by that the cross-linking of disulfides greatly restricted the diffusion of molten polymer chains participating in the crystallization [26], leading to a reduction in the crystallinity. Dynamic light scattering (DLS) results confirmed that MPNs were stable against a physiological salt concentration $(0.15 \mathrm{M}$ $\mathrm{NaCl}$ ) as well as a physiological $\mathrm{pH}(\mathrm{pH}$ 7.4): the average size of MPNs remained unchanged (Fig. 1d), while the size of the non-cross-linked self-assemblies of mPEGLA (Nanoparticles, NPs) gradually became undetectable or large aggregates were formed. Upon dilution to a low concentration of $10 \mu \mathrm{g} \mathrm{mL}^{-1}$, the size of MPNs still kept at about $170 \mathrm{~nm}$, indicating a good stability and dispersity (Additional file 1: Fig. S3).

\section{Redox sensitivity of MPNs and controlled dye release}

The redox responsiveness of MPNs was assessed by detecting changes in the size over time in a reductive environment similar to that in the extracellular matrix or in the cytoplasm. After they were exposed to $10 \mathrm{mM}$ GSH corresponding to an intracellular reductive condition, the size of MPNs rapidly expanded to about $400 \mathrm{~nm}$ as a result of cleavage of disulfide linkages and disassociation of PEG chains (Fig. 2a). In addition, MPNs maintained stable in the buffer with $10 \mu \mathrm{M}$ GSH analogous to an extracellular reductive environment. Subsequently, förster resonance energy transfer (FRET) experiment was employed to assess the encapsulation stability of MPNs [27]. The FRET pair dye consisting of lipophilic DiO (donor) and DiI (acceptor) was separately encapsulated in MPNs and NPs. If the dye molecules were stably trapped in the nanoparticles interior, no FRET would occur. But if the dye molecules were released from the nanoparticles and were within the förster radius, the $\mathrm{DiO}$ emission intensity decreased with development of FRET (Fig. 2b). When the DiO-containing NPs solution was mixed with the DiI-containing NPs solution, the DiO intensity rapidly decreased over time and the FRET ratio $I_{\mathrm{a}} /\left(I_{\mathrm{d}}+I_{\mathrm{a}}\right)$, where $I_{\mathrm{a}}$ and $I_{\mathrm{d}}$ were the fluorescence intensities of $\mathrm{DiO}$ and DiI, correspondingly increased (Fig. 2c and Additional file 1: Fig. S4). Notably, a much slower rate of FRET development was found in the solution of MPNs than that of NPs (Fig. 2d), confirming that disulfide cross-linking increased the encapsulation stability of the MPNs. The addition of $10 \mathrm{mM}$ GSH to the MPNs solution immediately triggered fast release of the loading dyes (Fig. 2f), while the dye release was not affected in the presence of $10 \mu \mathrm{M}$ GSH (Fig. 2e). The above results indicated that lipophilic molecules could be stably encapsulated in the MPNs during systemic circulation, but they could be rapidly released in an intracellular reductive environment after endocytosis.

\section{Tumor acidity-triggered size transition of MPNs}

To evaluate the $\mathrm{pH}$-sensitivity of MPNs, DLS was applied to measure their size change in water of different pHs ranging from 5.9 to 7.4. As shown in Fig. 3a, the size of MPNs varied from $\sim 170 \mathrm{~nm}$ at $\mathrm{pH} 7.4$ down to $\sim 20 \mathrm{~nm}$ at $\mathrm{pH} 6.5$. Therefore, we speculated that at $\mathrm{pH} 7.4$, cross-linked nanoparticles were susceptible to aggregating into large nanostructures because of intermicellar interactions through PEG corona [28], whereas at $\mathrm{pH}$ 6.5, the increased solubility of PEG in water and decreased inter-connection of PEG chains caused by the more effective hydrogen bonding of hydronium ions $\left(\mathrm{H}_{3} \mathrm{O}^{+}\right)$than water $\left(\mathrm{H}_{2} \mathrm{O}\right)$ to ethylene glycol units might lead to breakage of the supramolecular nanostructure and dissolution to individual cross-linked nanoparticles $[29,30]$. The particle size of the core cross-linked nanoparticles was smaller than that of NPs, which might be attributed to the more compact nanostructure of the core cross-linked nanoparticles after cross-linking of inner disulfide bonds [31,32]. The measured critical aggregation concentration of MPNs at $\mathrm{pH} 7.4\left(25.23 \mu \mathrm{g} \mathrm{mL}^{-1}\right)$ was 2.6-fold lower than that at pH $6.5\left(64.57 \mu \mathrm{g} \mathrm{mL}^{-1}\right.$, Additional file 1: Fig. S5). The morphology of MPNs viewed under a TEM directly evidenced that supramolecular aggregates appeared at $\mathrm{pH} 7.4$, but small nanoparticles around $10 \mathrm{~nm}$ at $\mathrm{pH}$ 6.5 (Fig. 3b), suggesting acid $\mathrm{pH}$-induced size change occurred for MPNs. Additionally, in the gel permeation chromatography (GPC) MPNs had a longer retention time at $\mathrm{pH} 6.5$ than those at $\mathrm{pH} 7.4$ (Fig. 3c), which further confirmed acid-activated dissolution of the superstructure into small particles. By the way, the dissolution of MPNs at $\mathrm{pH} 6.5$ did not accelerate the release of encapsulated dyes (Additional file 1: Fig. S6).

In light of a small size of MPNs at the tumoral acidity ( $\mathrm{pH}$ 6.5), it was reasonable to expect deep penetration of MPNs in tumor tissues. The diffusive transport of MPNs was evaluated using a collagen gel to stimulate the interstitial matrix of solid tumors in vitro. After pre-treatment at $\mathrm{pH} 7.4$ or 6.5 for $1 \mathrm{~h}, 10 \mu \mathrm{L}$ of FITC-labelled MPNs was placed in contact with the collagen gel and incubated at $37^{\circ} \mathrm{C}$ for another $12 \mathrm{~h}$. Confocal laser scanning microscopy (CLSM) was employed to gain an insight into the infiltration of both samples into the collagen gel (Fig. 3d). MPNs incubated at $\mathrm{pH} 7.4$ displayed limited penetration, while MPNs incubated at $\mathrm{pH} 6.5$ were able to penetrate a millimeter deep into the gel as a result of the dissolution of MPNs. 

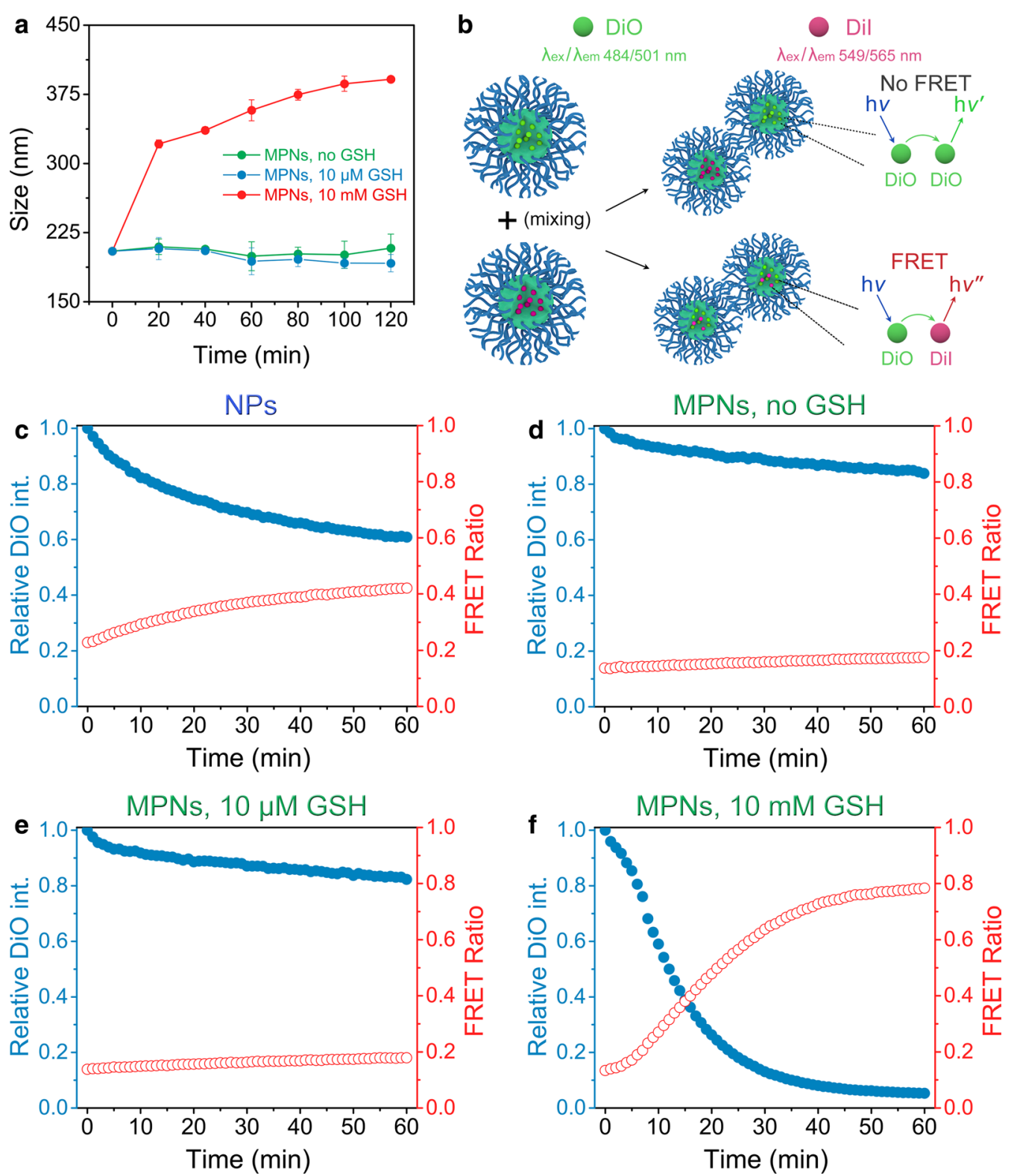

Fig. 2 Redox responsiveness of MPNs. a Time-dependent size changes of MPNs in response to different concentrations of GSH measured by DLS at $25^{\circ} \mathbf{C}(n=3)$. $\mathbf{b}$ Schematic presentation of the potential FRET outcomes. $\mathbf{c}, \mathbf{d}, \mathbf{e}, \mathbf{f}$ Time-dependent normalized (Norm.) emission intensity (int.) of DiO (blue solid dots, $\lambda$ ex $=450 \mathrm{~nm}, \lambda e m=510 \mathrm{~nm}$ ) and change in FRET ratio (red circles) for NPs and MPNs with GSH

\section{Drug loading and release}

In this work, hydrophobic doxorubicin (DOX) was used as a model drug and encapsulated into the nanoparticles to obtain DOX-loaded MPNs (D-MPNs) with a drug loading content of $11.94 \mathrm{wt} \%$. DLS and TEM results indicated that D-MPNs displayed similar well-defined supramolecular nanostructures as original MPNs with a diameter of about $160 \mathrm{~nm}$ (Fig. 4a). ${ }^{1} \mathrm{H}$ NMR spectra of free DOX, DOX-loaded nanoparticles (D-NPs) and D-MPNs also revealed some changes in the local environment of protons. A distinct change in the shape and position of DOX aromatic peaks was found after DOX was complexed with NPs or MPNs (Fig. 4b), indicating interactions among these chemical species [33]. The peaks of free DOX molecules at 7.33, 7.39 and $7.60 \mathrm{ppm}$ were shifted downfield after complexation with NPs and MPNs, and the peaks of D-MPNs had more significant chemical shifts than those of D-NPs. Moreover, the signal-to-noise ratio of DOX when complexed with MPNs was significantly improved in comparison 


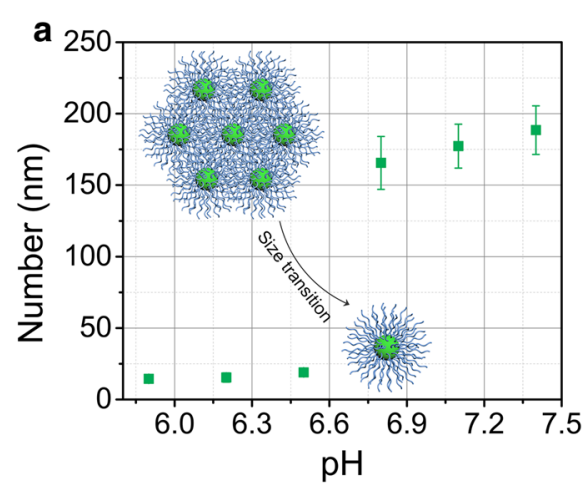

b
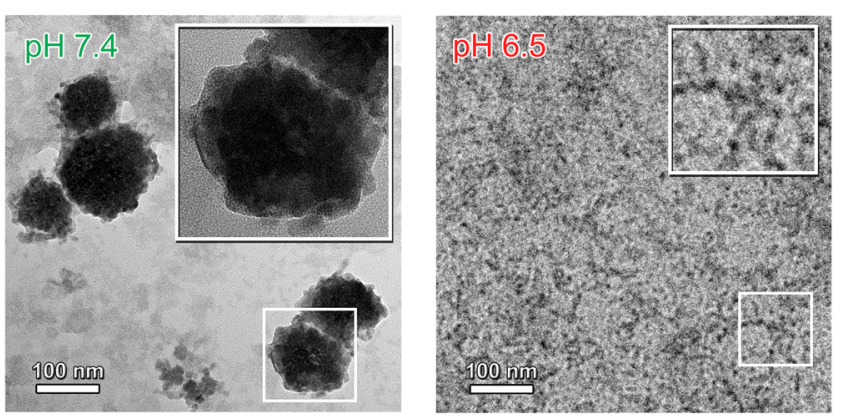

C

d
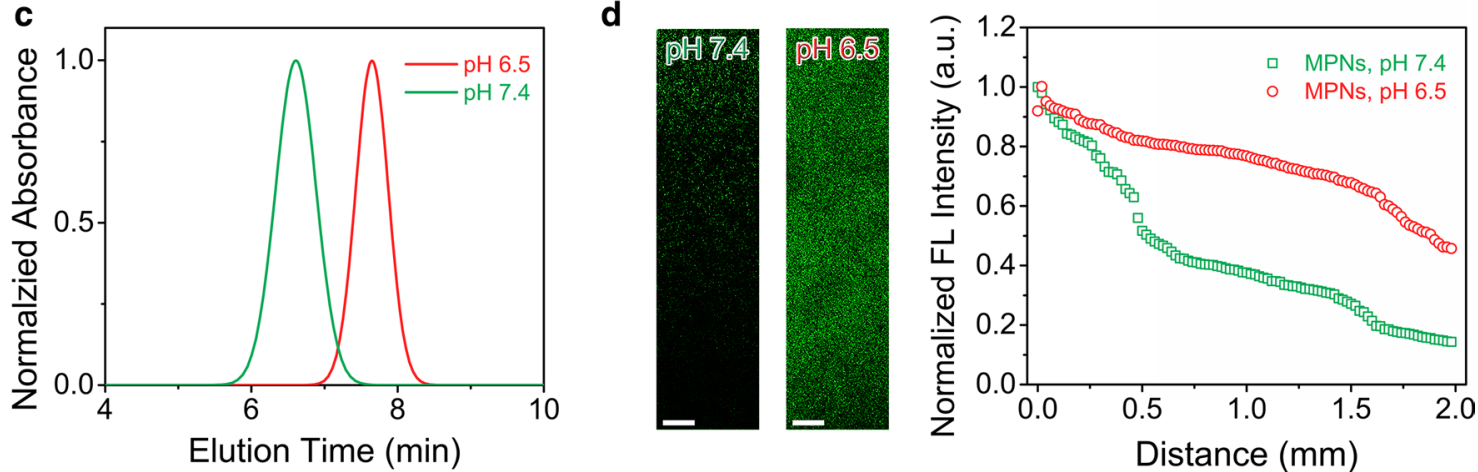

Fig. 3 Tumor acidity-triggered size transition of MPNs. a Particle size of MPNs at different pH values. $\mathbf{b}$ TEM measurements of MPNs treated at pH 7.4 and 6.5. Insert: high magnification TEM image of MPNs. The NPs and MPNs were stained with 2 wt \% phosphotungstic acid. c Gel permeation chromatography analysis of MPNs treated at pH 7.4 and 6.5. $\mathbf{d}$ Penetration profile of FITC-labeled MPNs (left panel) into the collagen hydrogel and normalized fluorescent intensity (right panel) of FITC-labeled MPNs in collagen hydrogels at pH 7.4 and 6.5. Scale bars: $125 \mu \mathrm{m}$

with that from D-NPs, which could be attributed to much more increased solubility of DOX in MPNs upon complexation.

The in vitro DOX release from D-MPNs under various biomimetic conditions were determined at a low concentration of $100 \mu \mathrm{g} \mathrm{mL}^{-1}$. As seen in Fig. 4c, burst release of DOX from D-NPs was observed under a normal physiological condition ( $\mathrm{pH}$ 7.4), with the cumulative release up to $60 \%$ within $2 \mathrm{~h}$, while a very slow DOX release from D-MPNs was observed in the same environment, due to their extremely stable nanostructure. At $\mathrm{pH} 6.5$ with $10 \mu \mathrm{M}$ GSH mimicking a tumor extracellular microenvironment, the DOX release rate was quite similar to that at $\mathrm{pH}$ 7.4. As expected, the intracellular reductive condition (10 mM GSH) triggered rapid DOX release from D-MPNs, and about 80\% DOX was released within $24 \mathrm{~h}$.

\section{In vitro antitumor activity}

The in vitro antitumor activity of D-MPNs against mouse breast $4 \mathrm{~T} 1$ tumor cells was determined by CCK- 8 assays. The MPNs up to a high concentration of $1 \mathrm{mg} \mathrm{mL}^{-1}$ were nontoxic to $4 \mathrm{~T} 1$ cells, while D-MPNs exhibited much stronger antitumor effects against $4 \mathrm{~T} 1$ cells in comparison with D-NPs and DOX (Fig. $4 \mathrm{~d}$ ). The $\mathrm{IC}_{50}$ value (the concentration for inhibiting 50\% of cell growth) for D-MPNs to $4 \mathrm{~T} 1$ cells was $0.55 \mu \mathrm{g} \mathrm{mL} \mathrm{m}^{-1}$, which was lower than that of D-NPs $\left(0.91 \mu \mathrm{g} \mathrm{mL}{ }^{-1}\right)$ and DOX $\left(1.63 \mu \mathrm{g} \mathrm{mL}^{-1}\right)$, this could be attributed to an improving bioavailability of the poorly soluble DOX by D-MPNs. Given the excellent antitumor effect of D-MPNs, a fluorescence-activated cell sorter (FACS) was utilized to assess drug internalization of D-MPNs. After exposure to different formulations for $3 \mathrm{~h}$, the stronger fluorescence intensity was detected in D-MPN-treated cells (Additional file 1: Fig. S7), supporting that MPNs could efficiently promote cellular uptake of the antitumor drug DOX. Since DOX played its therapeutic role in the nuclei, delivery of D-MPNs into the nuclei was further confirmed by Hoechst 33,342 staining (Additional file 1: Fig. S8). It was revealed from the CLSM images that after incubation for $3 \mathrm{~h}$, more DOX was delivered by MPNs into $4 \mathrm{~T} 1$ cells and the nuclei to exert its antitumor activity. To elucidate the role of bioreducibility in drug delivery through MPNs, 4T1 cells were pretreated with glutathione monoester (GSH-OEt) to up-regulate the intracellular GSH level and followed by incubation with D-MPNs [34]. Enhanced inhibition activity of D-MPNs was observed with GSH-OEt pretreated 4T1 

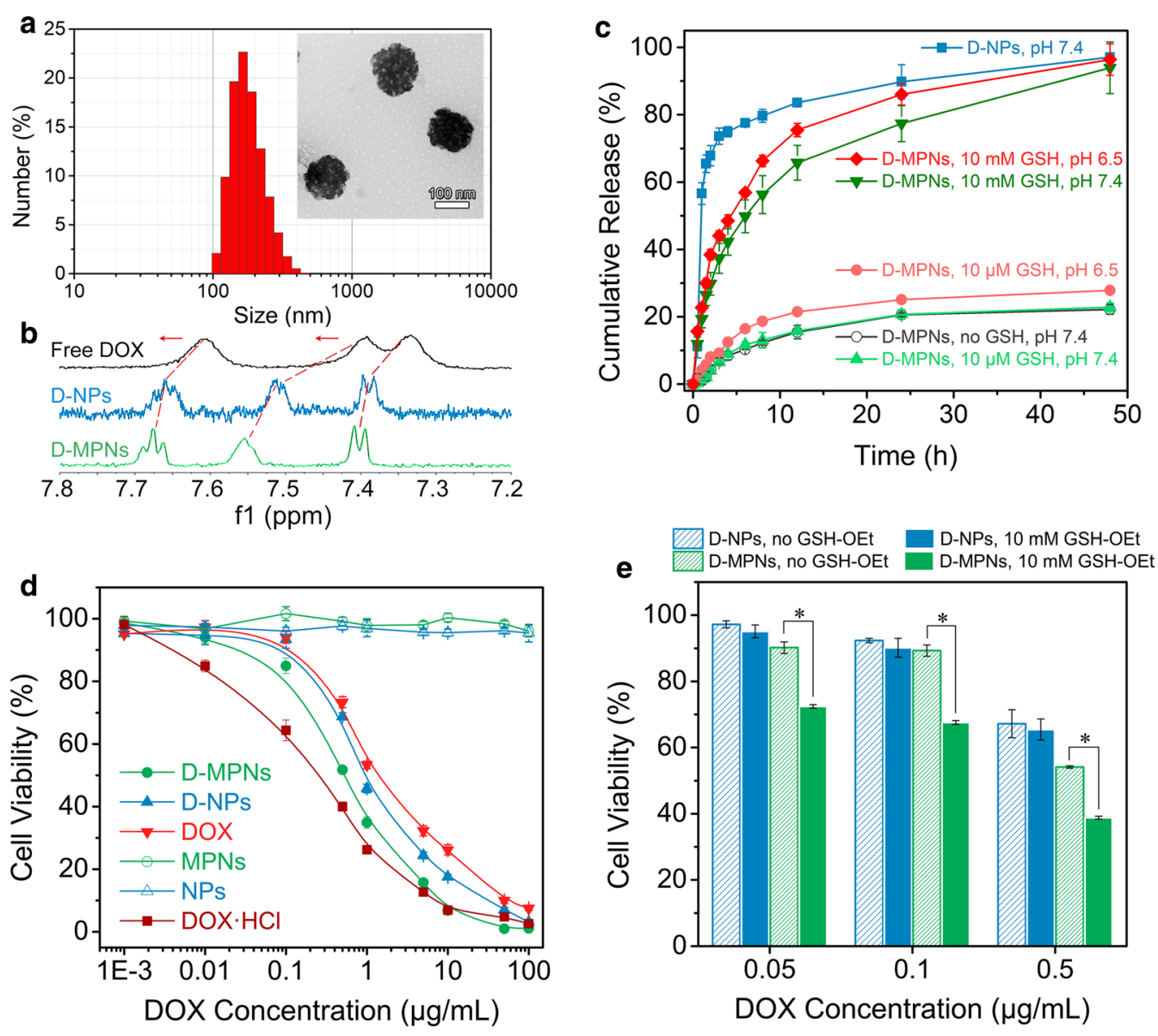

Fig. 4 a Size distribution and TEM image (the insert) of D-MPNs. Scale bar: $100 \mathrm{~nm}$. $\mathbf{b}$ Expansions of the ${ }^{1} \mathrm{H}$ NMR spectra $\left(600 \mathrm{MHz}, \mathrm{D}_{2} \mathrm{O}\right)$ of free DOX (top), D-NPs (middle) and D-MPNs (bottom). c Release of DOX from D-MPNs $\left(100 \mu \mathrm{g} \mathrm{mL}^{-1}\right.$ ) at different conditions mimicking physiological environments (means $\pm S D, n=3$ ). $\mathbf{d}$ Viabilities of $4 T 1$ cells after treatment with NPs, MPNs, DOX, D-NPs and D-MPNs for $48 \mathrm{~h}$ (means $\pm S D, n=5$ ). e Proliferation inhibition of 4T1 cells incubated with D-NPs and D-MPNs at various DOX concentrations for $48 \mathrm{~h}$. The cells were pretreated with $10 \mathrm{mM}$ GSH-OEt for $2 \mathrm{~h}$. The cells non-pretreated with GSH-OEt were used as control, $\left({ }^{*} p<0.05\right)$

cells (Fig. 4e), since a high level of GSH could facilitate the breakage of cross-linked nanostructure and greatly accelerate the release of antitumor drugs to inhibit the tumor cell proliferation.

\section{Penetration in MTSs and tumor tissues}

The tumor penetration efficacy of MPNs in the tumor tissue was evaluated through multicellular tumor spheroids (MTSs) with a diameter of about $200 \mu \mathrm{m}$ as an in vitro tumor model. It has been demonstrated that MTSs could be served as a realistic and suitable three-dimensional model of solid tumors for investigating tumor biology and screening anticancer drugs by mimicking the complicated multicellular architecture and the biological microenvironment of solid tumors [35]. 4T1 MTSs were incubated with DOX, D-NPs or D-MPNs for $3 \mathrm{~h}$ at $\mathrm{pH}$ 7.4 and 6.5, respectively. Low-intensity fluorescence signals were seen on each equatorial section of 4T1 MTSs after treatment with DOX (Fig. 5a), due to intrinsic poor distribution of hydrophobic drugs. Meanwhile, D-MPNs showed a better penetration behavior than D-NPs at either $\mathrm{pH} 7.4$ or 6.5 , which may be ascribed to the disulfide cross-linked nanostructure of MPNs. There was no obvious difference in distribution of DOX or D-NPs in MTSs at both $\mathrm{pH}$ values. But excitingly, the penetration ability of D-MPNs at a $\mathrm{pH}$ of 6.5 was remarkably improved, and the percentage of DOX-positive cells in MTSs increased from $39.0 \%$ at $\mathrm{pH} 7.4$ to $67.1 \%$ at $\mathrm{pH} 6.5$ which was determined from FACS analysis (Additional file 1: Fig. S9), The enhanced drug penetration ability of D-MPNs may be due to acidic $\mathrm{pH}$-stimulated rapid shrinkage of MPNs into small-sized nanoparticles.

The intratumoral drug distribution was further evaluated via cryosection of tumor tissues from mice bearing 4T1 tumors. From the CLSM images, it was seen that the red fluorescence intensity from $\mathrm{DOX} \cdot \mathrm{HCl}$ and 

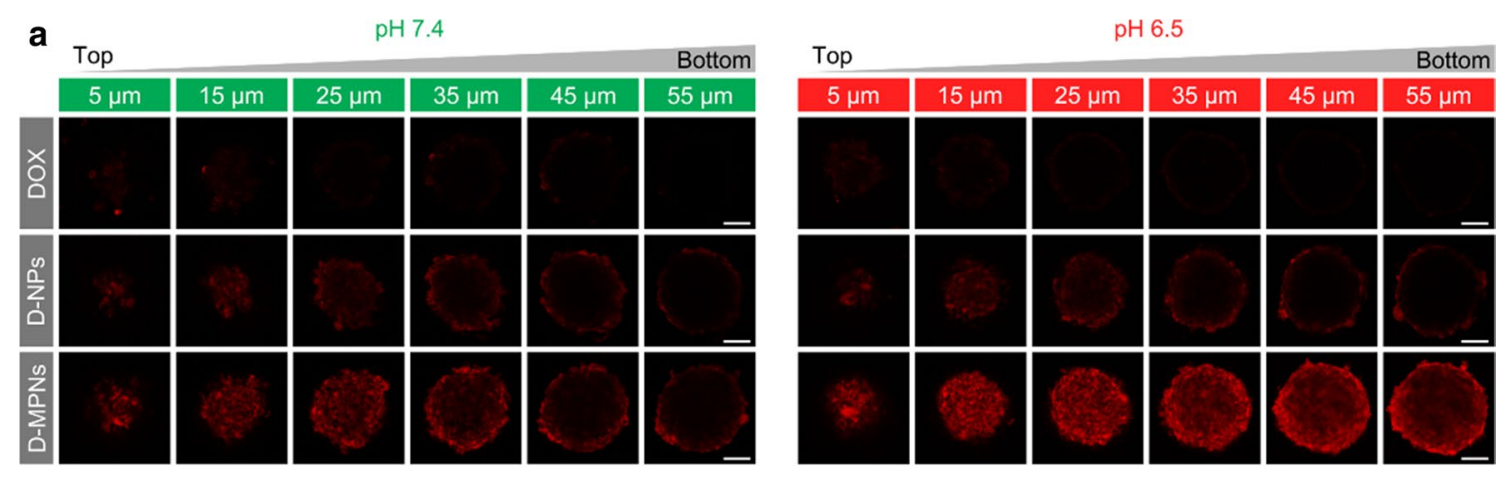

b
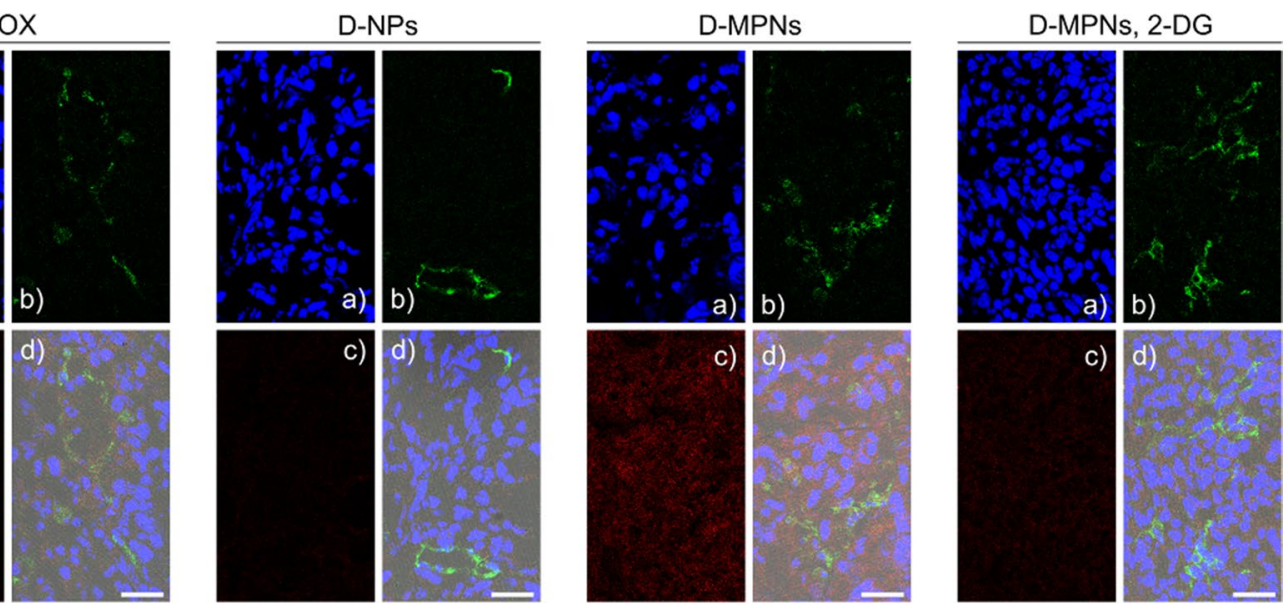

Fig. 5 In vitro and in vivo drug penetration D-MPNs. a CLSM images of 4T1 multicellular tumor sections at a distance of 5, 15, 25, 35, 45 and 55 $\mu \mathrm{m}$ from the spheroid rim. The MTSs were incubated with DOX, D-NPs and D-MPNs in the culture media at pH 7.4 or 6.5 for $2 \mathrm{~h}$ (DOX concentrations: $5 \mu \mathrm{g} \mathrm{mL}^{-1}$ ). Scale bars: $50 \mu \mathrm{m}$. b CLSM image of $4 \mathrm{~T} 1$ tumor sections after administration with DOX, D-NPs and D-MPNs for $12 \mathrm{~h}$ at a DOX dosage of $10 \mathrm{mg} \mathrm{kg}^{-1}$. Nuclei were stained by Hoechst 33,342 (a, blue) and blood vessels by FITC-CD31 (b, green). DOX fluorescence was visualized in red (c) and the merged imaged in (d). Scale bars: $30 \mu \mathrm{m}$

D-NPs was quite weak around the FITC-anti-CD31stained blood vessels, while the fluorescent intensity from D-MPNs was significantly enhanced and the signals spread much farther away from the tumor blood vessels (Fig. 5b). It is known that solid tumors have an acidic intratumoral microenvironment generated by an aerobic glycolysis [36]. To further confirm tumor acidity-activated penetration of D-MPNs in vivo, 2-deoxy-D-glucose (2-DG), a glycolytic inhibitor, was intratumorally injected to suppress uptake of glucose by tumor cells and prevent acidification in the tumoral microenvironment [37]. As shown in Fig. 5b, in the presence of 2-DG the penetration ability of D-MPNs significantly reduced as evidenced with attenuated fluorescence signals. The reduced penetration may be explained by inhibited acidification of the intratumoral environment and subsequent size decrease of MPNs. These results supported that intratumoral penetration of MPNs was tumor acidity-dependent in the in vitro MTSs model and in vivo mouse model.

\section{Pharmacokinetics, biodistribution and in vivo antitumor activity}

With a PEGylated corona and a disulfide cross-linked stable nanostructure, D-MPNs was expected to have prolonged systemic circulation in vivo. The pharmacokinetics studies was conducted with normal mice following intravenous administration of DOX. $\mathrm{HCl}, \mathrm{D}-\mathrm{NPs}$ and D-MPNs at various time points and the DOX content in plasma was analyzed by HPLC. The temporal changes in the drug concentration (Fig. 6a) and the pharmacokinetic parameters (Additional file 1: Table S1) calculated by non-compartmental analysis revealed that MPNs remarkably increased the area under the curve (AUC) for DOX in blood, which was 6.2-fold greater than that for D-NPs and 10.8-fold for DOX.HCl. Meanwhile, the mean retention time (MRT) of D-MPNs was 12.9-fold and 80.5-fold of D-NPs and DOX. $\mathrm{HCl}$, respectively. In addition, the half-life period $\left(t_{1 / 2}\right)$ of D-MPNs $(18.09 \mathrm{~h})$ was much longer than that of D-NPs $(1.81 \mathrm{~h})$ and $\mathrm{DOX} \cdot \mathrm{HCl}$ (0.83 h). 

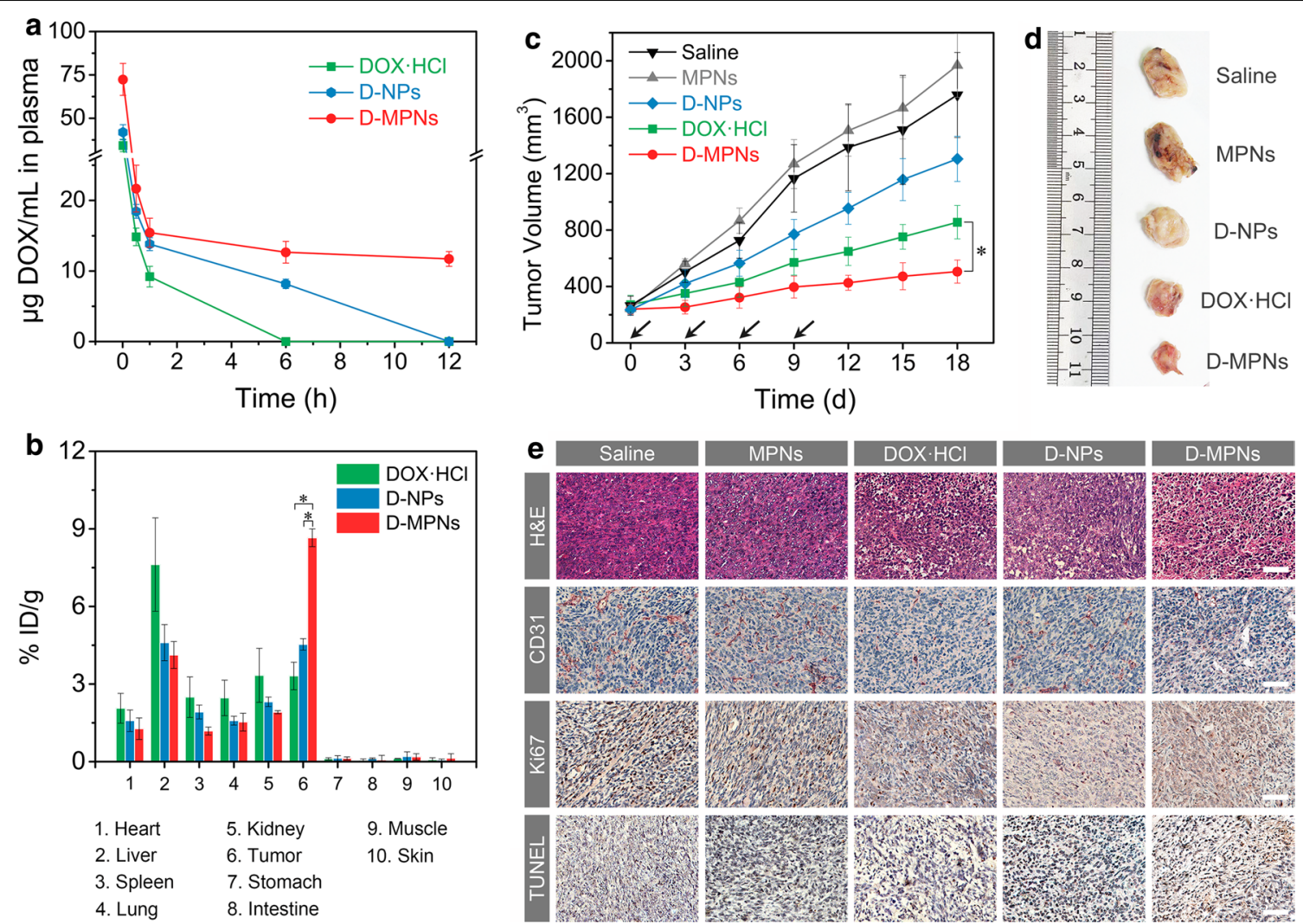

Fig. 6 Evaluation of in vivo antitumor efficacy. a In vivo pharmacokinetics of DOX.HCl, D-NPs or D-MPNs $(n=3)$. b Biodistribution of DOX.HCl, D-NPs and D-MPNs in mice at $12 \mathrm{~h}$ post-injection. c Tumor volumes of 4T1-bearing mice after intravenous administration with saline, MPNs, DOX.HCl, D-NPs and D-MPNs at a DOX dosage of $5 \mathrm{mg} \mathrm{kg}^{-1}\left(n=8,{ }^{*} p<0.01\right)$. The arrows indicate the times of intravenous tail vein performance. $\mathbf{d}$ Photographs of typical tumors collected on day 18. e Immunohistochemistry staining of 4T1 tumors. CD31-positive microvessels, Ki67-positive cells and TUNEL-positive cells were stained brown. Scale bars: $50 \mu \mathrm{m}$

The biodistribution of DOX in tumors and major organs at $12 \mathrm{~h}$ post-injection quantified by HPLC demonstrated that the mice treated with D-MPNs had a remarkably drug accumulation at the solid tumors of $8.6 \% \mathrm{ID} \mathrm{g}^{-1}$ (injected dose per gram of tissues), which was about 1.9 fold higher than that of D-NPs group and 2.6 fold higher than that of DOX. $\mathrm{HCl}$ group, respectively (Fig. $6 \mathrm{~b}$ ). Of note, the tumor accumulation of D-MPNs was also significantly higher than in the healthy organs such as heart, spleen, lung, and kidney.

Encouraged by the long blood circulation, enhanced tumor accumulation and deep tumor penetration, we evaluated the in vivo antitumor efficacy of D-MPNs on $\mathrm{BALB} / \mathrm{c}$ mice bearing large $4 \mathrm{~T} 1$ xenograft tumors (average size $250 \mathrm{~mm}^{3}$ ) following intravenous injection for 4 times. As presented in Fig. 6c, the tumor volumes of saline group increased to about $1800 \mathrm{~mm}^{3}$ after treatment over $18 \mathrm{~d}$. And the treatment of D-NPs resulted in slight suppression of tumor growth due to an unstable nanostructure and immature drug release. Encouraging, D-MPNs showed remarkable tumor inhibition capacity on tumor growth, which was better than the DOX.HCltreated positive control group $\left({ }^{*} p<0.01\right)$. The tumors collected from mice treated with D-MPNs on day 18 was the smallest among all groups, which further confirmed the excellent antitumor efficacy of D-MPNs (Fig. 6d). Furthermore, hematoxylin and eosin (H\&E) staining of tumor slices manifested that the treatment by D-MPNs led to remarkable damage to tumor cells in the tumor tissue evidenced by a loose structure and distinct karyopyknosis, whereas abundant and compact tumor cells were observed in the saline- and MPNs-treated groups (Fig. 6e). CD31-positive vessels were effectively reduced after administration with D-MPNs. More importantly, the fewest Ki67-positive proliferating cells as well as the most TUNEL-positive apoptotic cells were detected in the tumor tissues after D-MPNs treatment (Additional file 1: Fig. S10).

Favorable biocompatibility is crucial for potential clinical application of delivery systems. And body weight change acts as a common indicator for systemic toxicity assessment. After intravenous injection, the mice treated 
with D-MPNs showed a slight increase of body weight, while $\mathrm{DOX} \cdot \mathrm{HCl}$ caused a severe weight loss of $\sim 7 \%$ (Additional file 1: Fig. S11). From blood routine analysis data, no differences in white blood cell (WBC), red blood cell (RBC), platelet (PLT) and hemoglobin (HGB) levels were observed in D-MPNs-treated group and saline-treated control group (Additional file 1: Fig. S12). No histopathological abnormality was found in $\mathrm{H} \& \mathrm{E}-$ stained sections of major organs in D-MPNs-treated group (Additional file 1: Fig. S13). In contrast, apoptotic bodies were found in heart tissues of $\mathrm{DOX} \cdot \mathrm{HCl}$ group by TUNEL staining (Additional file 1: Fig. S14). In general, these results demonstrated the excellent therapeutic efficiency and biocompatibility of D-MPNs, that was worthy for further research as a potential clinical antitumor agent.

\section{Conclusions}

In conclusion, we have successfully fabricated a novel dual-responsive multi-pocket nanoparticles derived from self-assembly and cross-linking of amphiphilic mPEGLA conjugates. The multi-pocket nanoparticles exhibited a long circulation time and tumor $\mathrm{pH}$-triggered size reduction into smaller nanoparticles, which facilitated deep penetration into the tumor tissue. Moreover, the multi-pocket nanoparticles offered stable nanostructures for drug encapsulation, while the intracellular reductive environment cleaved disulfide linkages and triggered rapid drug release. The DOX-loaded multi-pocket nanoparticles showed superior antitumor activities against large 4T1 tumor $\left(\sim 250 \mathrm{~mm}^{3}\right)$ bearing BALB/c mice with reduced side effects. Our facile fabrication of multipocket nanoparticles would provide a promising way in improving solid tumor penetration and achieving a great therapeutic efficacy.

\section{Experimental section}

\section{Synthesis of mPEG-LA conjugates}

mPEG (3.00 g, Mw 1000), lipoic acid (0.93 g, $4.50 \mathrm{mmol})$, $\mathrm{EDC} \cdot \mathrm{HCl}(0.86 \mathrm{~g}, 4.50 \mathrm{mmol})$ and HOBT (0.61 g, $4.50 \mathrm{mmol})$ were dissolved in dichloromethane $(\sim 50 \mathrm{~mL})$ under nitrogen atmosphere. After cooled at $0{ }^{\circ} \mathrm{C}$ for $30 \mathrm{~min}$, DIPEA $(2.0 \mathrm{~mL}, 12.00 \mathrm{mmol})$ was added dropwise into the mixture. After reaction at room temperature for $12 \mathrm{~h}$, the mixed solution was washed with saturated $\mathrm{NaHCO}_{3}$ and $\mathrm{NaCl}$ solution 3 times and dried with $\mathrm{MgSO}_{4}$ overnight. The crude product was purified by column chromatography using dichloromethane: methanol (v:v =50:1) as an eluent. ${ }^{1} \mathrm{H}$ NMR $(400 \mathrm{MHz}$, $\left.\mathrm{CDCl}_{3}\right): \delta=4.26-4.19\left(\mathrm{t}, \mathrm{CH}_{2} \mathrm{OCO}\right), 3.65\left(\mathrm{~m}, \mathrm{CH}_{2} \mathrm{CH}_{2} \mathrm{O}\right)$, 3.58-3.53 (m, $\left.\mathrm{SSCH}_{2} \mathrm{CH}_{2} \mathrm{CH}\right), 3.38\left(\mathrm{~s}, \mathrm{CH}_{3} \mathrm{O}\right), 3.22-$ 3.07 (m, SSCH $\left.\mathrm{CH}_{2} \mathrm{CH}\right), 2.46\left(\mathrm{SSCH}_{2} \mathrm{CH}_{2} \mathrm{CH}\right), \quad 2.35$ (t, $\left.\mathrm{CH}_{2} \mathrm{COO}\right), 1.91$ (m, $\left.\mathrm{SSCH}_{2} \mathrm{CH}_{2} \mathrm{CH}\right), 1.76-1.59$ (m, $\mathrm{CH}_{2} \mathrm{CH}_{2} \mathrm{CH}_{2} \mathrm{CHS}$ ), 1.51 (m, $\mathrm{CH}_{2} \mathrm{CH}_{2} \mathrm{CH}_{2} \mathrm{CHS}$ ).

\section{Self-assembly of mPEG-LA conjugates}

Pyrene was used as a hydrophobic fluorescent probe to detect the critical assembly concentration (CAC) of mPEG-LA conjugates. Briefly, the concentration of pyrene was fixed at $0.67 \mu \mathrm{M}$ and the concentrations of mPEG-LA varied from 0.1 to $1000 \mu \mathrm{g} \mathrm{mL}^{-1}$. The excitation spectra of pyrene were recorded from 300 to $380 \mathrm{~nm}$ using a fluorescence spectrometer (Hitachi F-7000) with an emission wavelength of $395 \mathrm{~nm}$. The CAC was estimated according to the intersection of the curves when extrapolating the intensity ratio $I_{338} / I_{334}$ at low and high concentration regions.

\section{Preparation of MPNs and drug loaded MPNs}

MPNs were prepared by adding a catalytic amount of DTT (10 mol\% to lipoyl units) into mPEG-LA solution under a nitrogen atmosphere. After reaction for $24 \mathrm{~h}$, the solution was dialyzed against water in a dialysis tube (Spectra/Por, MWCO 2000) and lyophilized. DOX was loaded into MPNs by adding a mixed solution of mPEGLA conjugates $(15 \mathrm{mg}$ ) and DOX (3 mg) in DMSO into $30 \mathrm{~mL}$ of water containing catalytic amount of DTT under an ultrasound condition. After $24 \mathrm{~h}$, the solution was transferred to a dialysis tube (Spectra/Por MWCO 2000) and dialyzed against distilled water. One day later, the supernatant were lyophilized and the drug loading content (DLC) was determined by fluorescence measurement (excitation at $480 \mathrm{~nm}$ and emission at $550 \mathrm{~nm}$ ).

\section{In vitro drug release}

The release of DOX from DOX-loaded nanoparticles (D-NPs) and D-MPNs was studied in phosphate buffer (10 mM, pH 7.4 or pH 6.5) with or without GSH $(10 \mu \mathrm{M}$ or $10 \mathrm{mM})$. D-MPNs and D-NPs were prepared at a polymer concentration of $100 \mu \mathrm{g} \mathrm{mL} \mathrm{m}^{-1}$ (close to CAC) and transferred into dialysis tubes (MWCO 1000). The tubes were suspended in $25 \mathrm{~mL}$ of media. The samples were shaken at $120 \mathrm{rpm}$ and $37{ }^{\circ} \mathrm{C}$. At different intervals, $1 \mathrm{~mL}$ of the medium in the tube was taken away for fluorescence measurement and $1 \mathrm{~mL}$ of fresh medium was supplemented. The amount of DOX released was quantified by a fluorescence spectrometer (excitation at $480 \mathrm{~nm}$ and emission at $550 \mathrm{~nm}$ ).

\section{FRET measurements}

A solution of MPNs encapsulating DiI $(0.1 \mathrm{wt} \%, 500 \mu \mathrm{L}$ of $0.2 \mathrm{mg} \mathrm{mL}^{-1}$ stock) was added to a solution of MPNs encapsulating $\mathrm{DiO}\left(0.1 \mathrm{wt} \%, 500 \mu \mathrm{L}\right.$ of $0.2 \mathrm{mg} \mathrm{mL}^{-1}$ stock). The fluorescence spectra over time were recorded at an excitation wavelength of $450 \mathrm{~nm}$. And the FRET 
ratios were obtained from the equation $I_{\mathrm{a}} /\left(I_{\mathrm{d}}+I_{\mathrm{a}}\right)$, where $I_{\mathrm{a}}$ and $I_{\mathrm{d}}$ were the fluorescence intensities at $570 \mathrm{~nm}$ and $510 \mathrm{~nm}$, respectively.

\section{Collagen gel diffusion}

Collagen hydrogels were prepared by mixing $141.75 \mu \mathrm{L}$ of rat tail collagen type I $\left(5 \mathrm{mg} \mathrm{mL}^{-1}\right), 3.8 \mu \mathrm{L}$ of sodium hydroxide $(1 \mathrm{M})$ and $19.5 \mu \mathrm{L}$ of EDTA $(0.17 \mathrm{M})$ in order on ice. After vortexing for $5 \mathrm{~min}$, the gel was carefully applied to a microslide capillary tube (Vitrocom no. 2540) and incubated at $37{ }^{\circ} \mathrm{C}$ for $12 \mathrm{~h}$. Then, $10 \mu \mathrm{L}$ of FITC-labeled MPNs solutions $\left(1.0 \mathrm{mg} \mathrm{mL}^{-1}\right)$ after incubation at $\mathrm{pH} 7.4$ or $\mathrm{pH} 6.5$ for $1 \mathrm{~h}$ were added into the capillary tube and incubated at $37{ }^{\circ} \mathrm{C}$ for another $12 \mathrm{~h}$. A CLSM (Leica TCP SP5) was used to capture the images. And the images were analyzed using a software Image J.

\section{In vitro drug penetration}

Multicellular tumor spheroids from 4T1 cells were prepared by the method as previously reported38. Briefly, $2 \times 10^{5}$ of $4 \mathrm{~T} 1$ cells in $2 \mathrm{~mL}$ of RMPI 1640 medium were seeded into 6-well plates whose bases coated with $2 \mathrm{~mL}$ of $1 \%$ agarose per well. When reached about $200 \mu \mathrm{m}$ in diameter, these MTSs were transferred to a new glassbottomed dishes and treated with DOX, D-NPs or D-MPNs in the $\mathrm{pH} 7.4$ or 6.5 culture media at a DOX concentration of $5 \mu \mathrm{g} \mathrm{mL} \mathrm{m}^{-1}$ for $2 \mathrm{~h}$. The MTSs were then gently washed with PBS 3 times and viewed with a CLSM. For quantification, the MTSs treated with DOX formulations were dissociated into single cells by accutase regent (Invitrogen, USA) and the DOX fluorescence was detected with flow cytometry.

\section{In vitro cytotoxicity}

The cytotoxicity of D-MPNs to 4T1 cells was evaluated by CCK- 8 assays. The cells were cultured in 96-well plates at a density of $5 \times 10^{3}$ cells per well for $24 \mathrm{~h}$, followed by treatment with DOX.HCl, DOX, D-NPs or D-MPNs at different drug concentrations from 0.001 to $100 \mu \mathrm{g} \mathrm{mL} \mathrm{m}^{-1}$ for another $48 \mathrm{~h}$. After rinsing with PBS 3 times, the cells were incubated with $100 \mu \mathrm{L}$ of FBS-free medium containing $10 \%$ (v/v) CCK- 8 for additional $2 \mathrm{~h}$. The absorbance data at $450 \mathrm{~nm}$ were measured by a Varioskan Flash microplate reader (Thermo Fisher Scientific, USA). And the cell viabilities were determined according to the following formula: cell viability $(\%)=\left(\mathrm{OD}_{\text {sample }}-\mathrm{OD}_{\text {background }}\right) /$ $\left(\mathrm{OD}_{\text {control }}-\mathrm{OD}_{\text {background }}\right) \times 100 \%$.

To elucidate the influence of intracellular GSH on the cytotoxicity of D-MPNs, cells were pretreated with GSHOEt $(10 \mathrm{mM})$ for $2 \mathrm{~h}$. After exposure to D-MPNs at a DOX concentration ranging from 0.05 to $5 \mu \mathrm{g} \mathrm{mL}^{-1}$ for $48 \mathrm{~h}$, the cell viability was determined by CCK- 8 assays.

\section{In vivo antitumor effect}

When the tumor volumes reached about $250 \mathrm{~mm}^{3}$, the mice were randomly assigned into 4 groups $(n=8)$. Animals were intravenously administrated with saline, MPNs, DOX.HCl, D-NPs or D-MPNs every 3 days for 4 times (injection dose: $5 \mathrm{mg}$ DOX/kg body mass). The tumor volume $(V)$ was calculated from the equation: $V$ $\left(\mathrm{mm}^{3}\right)=l \cdot w^{2} / 2$, where $l$ and $w$ were the length and width of tumor. The relative body weight $\left(\mathrm{w} / \mathrm{w}_{0}\right)$ was calculated by the equation: $\mathrm{w} / \mathrm{w}_{0}=$ (body weight) /(body weight when the treatment was initiated).

\section{Histological and immunohistochemical analyses}

At the end of the treatment course, solid tumors and major organs were excised, fixed in $4 \%(\mathrm{v} / \mathrm{v})$ formalin solution and made of paraffin sections. These sections were further stained with terminal deoxynucleotidyl transferase mediated UTP end labeling (TUNEL), platelet endothelial cell adhesion molecules-1 (CD31), nuclear nonhistone protein Ki67 and hematoxylin and eosin $(\mathrm{H} \& \mathrm{E})$. Then the tissue slices were observed with an inverted fluorescence microscope (Leica DMI 4000B, Germany).

\section{In vivo biodistribution}

4T1 tumor-bearing $\mathrm{BALB} / \mathrm{c}$ mice were administrated with DOX.HCl, D-NPs or D-MPNs suspension $\left(10 \mathrm{mg} \mathrm{kg}{ }^{-1} \mathrm{DOX}\right)$. At $12 \mathrm{~h}$ post-administration, the major organs and tumors were collected and weighed. The tissues were homogenized in a $\mathrm{KH}_{2} \mathrm{PO}_{4}$ solution $\left(10 \mathrm{~mL} \mathrm{~g}^{-1}\right.$ tissue), and then DOX was extracted by chloroform and isopropanol $(\mathrm{v} / \mathrm{v}, 4: 1)$. After centrifugation at $10,000 \mathrm{rpm}$, the organic layer was transferred to a clean tube to evaporate under a gentle stream of nitrogen. The residue was dissolved in acetonitrile for HPLC analysis.

\section{Tumor penetration in vivo}

The mice bearing 4T1 tumors were intravenously administrated with DOX.HCl, D-NPs or D-MPNs at a $10 \mathrm{mg} \mathrm{kg}^{-1}$ dose of DOX. After $12 \mathrm{~h}$, the tumors were separated from mice for frozen sections at a thickness of $8 \mu \mathrm{m}$ on an equatorial plane. The sections were fixed in acetone for $10 \mathrm{~min}$, blocked in a blocking buffer (PBS with 5\% BSA) for $1 \mathrm{~h}$ and incubated with FITC-CD31 antibody for $1.5 \mathrm{~h}$. After washed with PBS 3 times, the samples were stained with Hoechst 33,342 and observed under a CLSM. To demonstrate the acid-triggered deep penetration of nanoparticles, a tumor glycolysis inhibitor 2-DG was intratumorally injected $\left(250 \mathrm{mg} \mathrm{kg}^{-1}\right) 12 \mathrm{~h}$ before administration of D-MPNs. 


\section{Pharmacokinetic studies}

$\mathrm{BALB} / \mathrm{c}$ mice (female, $\sim 20 \mathrm{~g}$ ) were administrated with DOX. $\mathrm{HCl}, \mathrm{D}-\mathrm{NPs}$ or D-MPNs via their tail veins at a $10 \mathrm{mg} \mathrm{kg}^{-1}$ dose of DOX. After a predetermined time, blood samples were collected via eyeball extirpating into heparinized tubes and centrifuged at $3000 \mathrm{rpm}$ to obtain the plasma. $100 \mu \mathrm{L}$ of plasma was mixed with $50 \mu \mathrm{L}$ of $5 \mathrm{M} \mathrm{HCl}$ and kept at $50{ }^{\circ} \mathrm{C}$ for $1.5 \mathrm{~h}$. Followed by mixed with $50 \mu \mathrm{L}$ of $1 \mathrm{M} \mathrm{NaOH}$, the mixture was extracted with chloroform/isopropanol (v/v, 4:1). After centrifugation $(10,000 \times \mathrm{g}, 5 \mathrm{~min})$, the organic phase was transferred to a new tube, evaporated under vacuum, and re-dissolved in $100 \mu \mathrm{L}$ of mobile phase, acetonitrile: water (v/v, 7:3) with $0.1 \%(\mathrm{v} / \mathrm{v})$ TFA for HPLC analysis.

\section{Supplementary Information}

The online version contains supplementary material available at https://doi. org/10.1186/s12951-021-00854-z.

Additional file 1: Fig. S1. ${ }^{1} \mathrm{H}$ NMR spectrum $(400 \mathrm{MHz})$ of mPEG-LA conjugates in $\mathrm{CDCl}_{3}$. Fig. S2. SEM image (A), size (B) and zeta potential (C) of the self-assembly of mPEG-LA conjugates (NPs, $100 \mathrm{~g} \mathrm{~mL}^{-1}$ ). Fig. S3. Size distribution of MPNs at different concentrations. Fig. S4. Fluorescence spectra of a mixed solution of NPs $\left(100 \mu \mathrm{g} \mathrm{mL}^{-1}\right)$ and MPNs $\left(100 \mu \mathrm{g} \mathrm{mL}^{-1}\right)$ prepared with $0.1 \mathrm{wt} \% \mathrm{DiO} / \mathrm{Dil}$ tracing the development of FRET between two dyes. Fig. S5. Critical aggregation concentration of MPNs at (A) pH 7.4 or (B) 6.5. Fig. S6. Fluorescence spectra of a mixed solution of MPNs (100 $\mu \mathrm{g} \mathrm{mL}^{-1}, \mathrm{pH}$ 6.5) prepared with $0.1 \mathrm{wt} \%$ DiO/Dil tracing the development of FRET between two dyes over time. Fig. S7. Flow cytometric histogram profiles of 4 T1 cells treated with MPNs, DOX, D-NPs and D-MPNs for 3 $\mathrm{h}$ (DOX concentration: $10 \mu \mathrm{g} \mathrm{mL}{ }^{-1}$ ). Fig. S8. CLSM images of $4 \mathrm{~T} 1$ cells incubated with DOX, D-NPS, D-MPNs and DOX.HCl for $1 \mathrm{~h}$ (DOX dosage: $2 \mu \mathrm{gL}^{-1}$ ). Hoechst 33342 was used to stain the cell nuclei. Scale bar: 10 $\mu \mathrm{m}$. Fig. S9. Quantitative assessment of penetration of DOX formulations into 4T1 cells. The cells were incubated with DOX, D-NPs and D-MPNs at a DOX concentration of $5 \mu \mathrm{g} \mathrm{mL}^{-1}$ for $2 \mathrm{~h}$. Fig. S10. IOD (Integrated optical density) of immunohistochemical images for saline, MPNs, DOX.HCl, D-NPs and D-MPNs groups. The apoptotic rates of tumor sections based on TUNEL images (A), tumor microvessel density based on CD31 images (B) and Ki67 positive cells (C) of tumor sections were calculated with Image-Pro Plus 6.0 software. Data were presented as mean \pm SD $(n=$ 3), ${ }^{*} p<0.01,{ }^{* *} p<0.005$. Fig. S11. Body weight changes of $4 \mathrm{~T} 1$-bearing $\mathrm{BALB} / \mathrm{c}$ mice after administration with saline, MPNs, DOX.HCl, D-NPs and

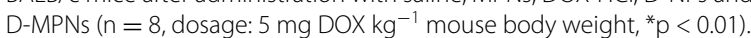
The arrows indicated the time points for intravenous injection. Fig. S12. Routine blood analysis results of the mice collected on the 12th day after intravenous injection of saline, MPNs, DOX.HCl, D-NPs or D-MPNs. The results show mean and standard deviation of white blood cells (WBCs), red blood cell (RBC), hemoglobin (HGB) and platelets (PLT). Fig. S13. Histological examination of major organs separated from 4T1-bearing BALB/C mice after administration with saline, MPNs, DOX.HCl, D-NPs and D-MPNs for 18 days. Scale bar: $100 \mu \mathrm{m}$. Fig. S14. TUNEL staining of heart ( $\times 200)$ of 4T1-bearing BALB/C mice after administration with saline, MPNs, DOX.HCl, D-NPs and D-MPNs for 18 days. The apoptotic cells (red arrow) and normal cells were stained brown and blue, respectively. Table S1. Pharmacokinetic parameters of DOX.HCI, D-NPs and D-MPNs after intravenous administration at an equivalent dose of $10 \mathrm{mg} \mathrm{DOX} / \mathrm{kg}$ mouse body weight ( $n=3$ per group).

\section{Acknowledgements}

Not applicable.

\section{Authors' contributions}

All authors contributed significantly to this work. XH, DZ, KL and ZG contributed to the design and conception of the subject. XH performed the experiments and written the paper; $\mathrm{DZ}$ and $\mathrm{YL}$ performed the animal experiments. XH, DZ and ZG contributed to data analysis; HM, JY and HZ edited the manuscript. KL and QG gave lots of guidance on paper submission. All authors read and approved the final manuscript.

\section{Funding}

This work was supported by The National Natural Science Foundation of China (Nos. 81621003, 51873120, 51673127, 31800803 and 31771067), the National Key Research and Development Program of China (No. 2017YFC1103501), the Key R\&D Plan of Jiangsu Province (No. BE2018010-3), and the Scientific Research Foundation for Talent Introduction of Nanjing Tech University (No. 39803130 and 39803129).

\section{Availability of data and materials}

All data generated or analyzed during this study are included in this article and its Additional file.

\section{Declarations}

\section{Ethics approval and consent to participate}

All animal procedures were performed in accordance with the Guidelines for Care and Use of Laboratory Animals of Sichuan University (Chengdu, China) and the experiments were approved by the ethics committee of Sichuan University (Chengdu, China).

\section{Consent for publication}

Not applicable.

\section{Competing interests}

The authors declare that they have no competing interests.

\section{Author details}

${ }^{1}$ Huaxi MR Research Center (HMRRC), Department of Radiology, Functional and Molecular Imaging Key Laboratory of Sichuan Province, National Clinical Research Center for Geriatrics, West China Hospital, Sichuan University, Chengdu 610041, People's Republic of China. ${ }^{2}$ Research Institute for Biomaterials, Tech Institute for Advanced Materials, College of Materials Science and Engineering, NJTech-BARTY Joint Research Center for Innovative Medical Technology, Nanjing Tech University, Nanjing 211816, People's Republic of China. ${ }^{3}$ The Key Laboratory of Bioactive Materials, Ministry of Education, College of Life Science, Nankai University, Tianjin 300071, People's Republic of China. ${ }^{4}$ Amgen Bioprocessing Centre, Keck Graduate Institute, Claremont, CA 91711, USA.

Received: 9 February 2021 Accepted: 7 April 2021

Published online: 19 April 2021

\section{References}

1. Kakkar A, Traverso G, Farokhzad OC, Weissleder R, Langer R. Evolution of macromolecular complexity in drug delivery systems. Nat Rev Chem. 2017;1:0063.

2. Nishiyama N, Matsumura Y, Kataoka K. Development of polymeric micelles for targeting intractable cancers. Cancer Sci. 2016;107:867-74.

3. Wang D, Jin Y, Zhu X, Yan D. Synthesis and applications of stimuli-responsive hyperbranched polymers. Prog Polym Sci. 2017;64:114-53.

4. Owen SC, Chan DP, Shoichet MS. Polymeric micelle stability. Nano Today. 2012;7:53-65

5. Yang C, Tan JPK, Cheng W, Attia ABE, Ting CTY, Nelson A, Hedrick JL, Yang Y-Y. Supramolecular nanostructures designed for high cargo loading capacity and kinetic stability. Nano Today. 2010;5:515-23.

6. Chen J, Ding J, Wang Y, Cheng J, Ji S, Zhuang X, Chen X. Sequentially responsive shell-stacked nanoparticles for deep penetration into solid tumors. Adv Mater. 2017;29:1701170. 
7. Deng Z, Yuan S, Xu RX, Liang H, Liu S. Reduction-triggered transformation of disulfide-containing micelles at chemically tunable rates. Angew Chem Int Ed. 2018;57:8896-900.

8. $\quad$ Yang W, Zou Y, Meng F, Zhang J, Cheng R, Deng C, Zhong Z. Efficient and targeted suppression of human lung tumor xenografts in mice with methotrexate sodium encapsulated in all-function-in-one chimeric polymersomes. Adv Mater. 2016;28:8234-9.

9. Li Y, Xiao W, Xiao K, Berti L, Luo J, Tseng HP, Fung G, Lam KS. Well-defined, reversible boronate crosslinked nanocarriers for targeted drug delivery in response to acidic $\mathrm{pH}$ values and cis-diols. Angew Chem Int Ed. 2012;51:2864-9.

10. Lee SJ, Min KH, Lee HJ, Koo AN, Rim HP, Jeon BJ, Jeong SY, Heo JS, Lee SC. Ketal cross-linked poly(ethylene glycol)-poly(amino acid)s copolymer micelles for efficient intracellular delivery of doxorubicin. Biomacromol. 2011;12:1224-33.

11. Li Y, Xiao K, Zhu W, Deng W, Lam KS. Stimuli-responsive cross-linked micelles for on-demand drug delivery against cancers. Adv Drug Deliver Rev. 2014;66:58-73.

12. Jain RK, Stylianopoulos T. Delivering nanomedicine to solid tumors. Nat Rev Clin Oncol. 2010;7:653-64.

13. Khawar IA, Kim JH, Kuh H-J. Improving drug delivery to solid tumors: priming the tumor microenvironment. J Controll Release. 2015;201:78-89.

14. Wang J, Mao W, Lock LL, Tang J, Sui M, Sun W, Cui H, Xu D, Shen Y. The role of micelle size in tumor accumulation, penetration, and treatment. ACS Nano. 2015;9:7195-206.

15. Cabral H, Matsumoto Y, Mizuno K, Chen Q, Murakami M, Kimura M, Terada Y, Kano MR, Miyazono K, Uesaka M, et al. Accumulation of sub-100 nm polymeric micelles in poorly permeable tumours depends on size. Nat Nanotechnol. 2011;6:815-23.

16. Zhou M, Huang H, Wang D, Lu H, Chen J, Chai Z, Yao SQ, Hu Y. Light-triggered PEGylation/dePEGylation of the nanocarriers for enhanced tumor penetration. Nano Lett. 2019;19:3671-5.

17. Zhou Z, Liu Y, Zhang M, Li C, Yang R, Li J, Qian C, Sun M. Size switchable nanoclusters fueled by extracellular ATP for promoting deep penetration and MRI-guided tumor photothermal therapy. Adv Funct Mater. 2019;29:1904144.

18. Li Y, Xu X, Zhang X, Li Y, Zhang Z, Gu Z. Tumor-specific multiple stimuliactivated dendrimeric nanoassemblies with metabolic blockade surmount chemotherapy resistance. ACS Nano. 2017;11:416-29.

19. Li H-J, Du J-Z, Liu J, Du X-J, Shen S, Zhu Y-H, Wang X, Ye X, Nie S, Wang J. Smart superstructures with ultrahigh $\mathrm{pH}$-sensitivity for targeting acidic tumor microenvironment: instantaneous size switching and improved tumor penetration. ACS Nano. 2016;10:6753-61.

20. Jin H, Zhu T, Huang X, Sun M, Li H, Zhu X, Liu M, Xie Y, Huang W, Yan D. ROS-responsive nanoparticles based on amphiphilic hyperbranched polyphosphoester for drug delivery: Light-triggered size-reducing and enhanced tumor penetration. Biomaterials. 2019;211:68-80.

21. Bai S, Zhang Y, Li D, Shi X, Lin G, Liu G. Gain an advantage from both sides: Smart size-shrinkable drug delivery nanosystems for high accumulation and deep penetration. Nano Today. 2021;36:101038.

22. Harris JM, Chess RB. Effect of pegylation on pharmaceuticals. Nat Rev Drug Discov. 2003;2:214-21.

23. Veronese FM, Pasut G. PEGylation, successful approach to drug delivery. Drug Discov Today. 2005;10:1451-8.
24. Liao C, Dai X, Chen Y, Liu J, Yao Y, Zhang S. Biogenic (R)-(+)-lipoic acid only constructed cross-linked vesicles with synergistic anticancer potency. Adv Funct Mater. 2019;29:1806567.

25. Maczurek A, Hager K, Kenklies M, Sharman M, Martins R, Engel J, Carlson DA, Münch G. Lipoic acid as an anti-inflammatory and neuroprotective treatment for Alzheimer's disease. Adv Drug Deliver Rev. 2008;60:1463-70.

26. Qiao C, Jiang S, Dong D, Ji X, An L, Jiang B. The critical lowest molecular weight for PEG to crystallize in cross-linked networks. Macromol Rapid Comm. 2004;25:659-63.

27. Zhong D, Wu H, Wu Y, Li Y, Xu X, Yang J, Gu Z. Rational design and facile fabrication of biocompatible triple responsive dendrimeric nanocages for targeted drug delivery. Nanoscale. 2019;11:15091-103.

28. Bhatia S, Mohr A, Mathur D, Parmar VS, Haag R, Prasad AK. Biocatalytic route to sugar-PEG-based polymers for drug delivery applications. Biomacromol. 2011;12:3487-98.

29. Kurniasih IN, Liang H, Kumar S, Mohr A, Sharma SK, Rabe JP, Haag R. A bifunctional nanocarrier based on amphiphilic hyperbranched polyglycerol derivatives. J Mater Chem B. 2013;1:3569-77.

30. Suh JM, Bae SJ, Jeong B. Thermogelling multiblock poloxamer aqueous solutions with closed-loop Sol-Gel-Sol transitions on increasing $\mathrm{pH}$. Adv Mater. 2005;17:118-20.

31. Gao Y, Dong C-M. Reduction- and thermo-sensitive core-cross-linked polypeptide hybrid micelles for triggered and intracellular drug release. Polym Chem. 2017;8:1223-32.

32. Hu J, He J, Cao D, Zhang M, Ni P. Core cross-linked polyphosphoester micelles with folate-targeted and acid-cleavable features for $\mathrm{pH}$-triggered drug delivery. Polym Chem. 2015;6:3205-16.

33. Al-Jamal KT, Al-Jamal WT, Wang JT-W, Rubio N, Buddle J, Gathercole D, Zloh M, Kostarelos K. Cationic poly-L-lysine dendrimer complexes doxorubicin and delays tumor growth in vitro and in vivo. ACS Nano. 2013;7:1905-17.

34. Liu J, Huang W, Pang Y, Huang P, Zhu X, Zhou Y, Yan D. Molecular selfassembly of a homopolymer: an alternative to fabricate drug-delivery platforms for cancer therapy. Angew Chem Int Ed. 2011;50:9162-6.

35. Pampaloni F, Reynaud EG, Stelzer EH. The third dimension bridges the gap between cell culture and live tissue. Nat Rev Mol Cell Bio. 2007;8:839-45.

36. Gatenby RA, Gillies RJ. Why do cancers have high aerobic glycolysis? Nat Rev Cancer. 2004;4:891-9.

37. Zhang D, Li J, Wang F, Hu J, Wang S, Sun Y. 2-Deoxy-D-glucose targeting of glucose metabolism in cancer cells as a potential therapy. Cancer Lett. 2014;355:176-83.

38. Zhong D, Xu X, Li Y, Wu H, Zhang Z, Yang J, Zhang H, Gong Q, Luo K, Gu $Z$. Entirely synthetic bacterial nanomimics for highly-effective tumor suppression and immune elicitation. Nano Today. 2020;35:100950.

\section{Publisher's Note}

Springer Nature remains neutral with regard to jurisdictional claims in published maps and institutional affiliations.

Ready to submit your research? Choose BMC and benefit from

- fast, convenient online submission

- thorough peer review by experienced researchers in your field

- rapid publication on acceptance

- support for research data, including large and complex data types

- gold Open Access which fosters wider collaboration and increased citations

- maximum visibility for your research: over $100 \mathrm{M}$ website views per year

At BMC, research is always in progress.

Learn more biomedcentral.com/submissions 